\title{
Retinoids in oncology: experimental and clinical aspects
}

\author{
Wemer Bollag \\ F. Hoffmann-La Roche Ltd., Pharmaceutical Research, CH-4002 Basle, Switzerland
}

\begin{abstract}
Retinoids are of particular interest in experimental and clinical oncology. They exert their antitumor activity through inhibition of cell proliferation, induction of cell differentiation, suppression of oncogene expression and inhibition of angiogenesis. In animal experiments, retinoids have preventive and therapeutic effects on premalignant and malignant lesions. Clinically, chemoprevention with isotretinoin and etretinate has been tested with some success. Therapeutic effects have also been observed with retinoid treatment of precancerous and cancerous conditions. Substantial therapeutic success has been achieved in the treatment of acute promyelocytic leukemia with tretinoin and of squamous cell carcinomas of the skin and cervix with a combination of isotretinoin and interferon $\alpha$.
\end{abstract}

\section{INTRODUCTION}

The retinoids are a class of chemical compounds structurally related to vitamin A and comprising natural and synthetic analogs. A correlation between vitamin A and cancer was first noted in the $1920 \mathrm{~s}$, when experimentally induced vitamin A-deficiency was shown to lead to preneoplastic lesions and ultimately to neoplasms (refs. 1-4). Forty years later, a preventive and therapeutic effect of vitamin A on chemically induced tumors was demonstrated in animal models. The antitumor effect was not only associated with vitamin A (retinol) but also with the natural metabolite all-trans-retinoic-acid (all-trans-RA), as well as other retinoids (refs. 5-7). This was the basis for the clinical use of retinoids in prevention and therapy of a variety of precancerous and neoplastic diseases (refs. 6-8). The following retinoids are of particular interest in experimental and clinical oncology: alltrans-RA (tretinoin), 13-cis-RA (isotretinoin) and 9-cis-RA, the aromatic retinoids etretinate and acitretin and the arotenoid Ro 40-8757 (Fig. 1).

\section{All-trans retinoic acid \\ Tretinoin \\ VESANOID ${ }^{\circledR}$}

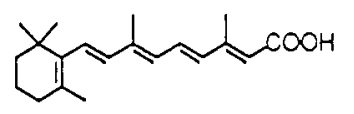

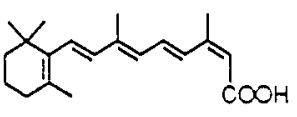

ROACCUTANE ${ }^{\circledR} /$ ACCUTANE $^{\circledR}$

9-cis retinoic acid

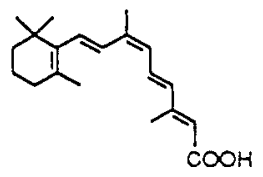

Fig. 1. Chemical structure of retinoids 


\section{CLINICAL USE OF RETINOIDS IN PREVENTION OF CANCER}

Preventive and inhibitory effects of retinoids on carcinogenesis have been shown in animal experiments with chemically induced tumors, e.g. skin (refs. 9,10), breast (ref. 11), bladder (ref. 12), lung and others (refs. 6,7,13). This has generated increasing interest in the use of retinoids for tumor prevention in man. However, in cancer prevention trials in a healthy population not belonging to a high-cancer-risk group, only those retinoids with virtually no acute or chronic toxicity would be acceptable. Unfortunately, no such retinoid is currently available for testing. Only in patients with a high genetic or environmental cancer risk (e.g. patients with xeroderma pigmentosum, individuals with family history of high susceptibility to cancer, cancer patients with an increased risk of developing second primary tumors within a relatively short time after removal of first primary, or individuals constantly exposed to carcinogenic substances) can prophylactic treatment with retinoids be seriously considered and prove to be beneficial. The risk/benefit ratio must, therefore, be taken into account.

Cancer prevention studies have been performed with positive results in the following indications: xeroderma pigmentosum (refs. 14-16), basal cell carcinoma (BCC) and squamous cell carcinoma (SCC) of the skin (refs. 17-19), SCC of the oral cavity (ref. 20), superficial bladder tumors (refs. 21,22), and second primary tumors in SCC of the aerodigestive tract (ref. 23). Patients suffering from xeroderma pigmentosum, a genetic disorder, tend to develop premalignant and malignant skin lesions with a 1000 -fold higher frequency than the general population. In a study of 5 patients with xeroderma pigmentosum, developing a total of 121 tumors during a 2year period before retinoid treatment, the number of new tumors including BCC and SCC was reduced to 25 during a 2-year treatment period with isotretinoin. Patients with organ transplants have shown a 20 -fold increased risk of skin cancer in Australia. Four male immunosuppressed renal-transplant recipients developed a total of 23 SCC of the skin in a 12-month period before retinoid treatment. During a treatment period of 8-13 months with daily etretinate, the number of newly diagnosed SCC decreased to six. However, prevention of SCC can only be maintained by continuous therapy with the retinoid. Patients with superficial bladder tumors removed by transurethral electrocoagulation or resection showed a reduced incidence of new bladder tumors. In the group receiving etretinate, $72 \%$ showed no recurrence compared to $35 \%$ in the placebo group. Patients with SCC of the oral cavity, pharynx or larynx, cured via surgery and/or radiotherapy, have an increased risk of developing a second primary tumor, not only in the head and neck area but also in the esophagus or lung. The incidence of these second primary tumors has been markedly reduced by preventive treatment with isotretinoin. In a prospective, randomized, placebo-controlled study, 100 patients with SCC of the oral cavity, pharynx or larynx, after completion of surgery or radiotherapy (or both), were randomly assigned to receive either isotretinoin or placebo for 12 months. After a median follow-up of $2 \frac{1}{2}$ years, only two patients $(4 \%)$ in the isotretinoin group had second primary tumors compared to $12(24 \%)$ in the placebo group. Four patients in the placebo group had multiple, second primary tumors. Except for an acute myeloid leukemia, all tumors were of the SCC type. Twelve patients treated with placebo had 17 new tumors in the head and neck area, in the esophagus and in the bronchopulmonary area. Patients treated with isotretinoin developed only two new tumors, one head and neck, and one esophageal cancer. The authors conclude from the significant suppression of second primary tumors by isotretinoin that these results provide the basis for further chemoprevention studies in subjects at high risk for all tobacco-related epithelial cancers.

\section{THERAPY OF PRECANCEROUS LESIONS}

It is widely assumed that cancerous lesions are preceded by precancerous lesions. Successful therapy of a precursor lesion might be equated with prevention of the threatening malignancy. A series of premalignant lesions of skin, oral cavity, larynx, bronchus, breast, cervix, vulva, bladder and bone marrow has responded to a certain degree to retinoids (ref. 24). Actinic keratosis responds to topical treatment with tretinoin ointment. Oral treatment of 105 patients with etretinate produced complete remission in $45(43 \%)$ and partial remission in $49(47 \%)$. Oral leukoplakia, a precancerous condition, does not respond well to conventional treatment. Of 97 patients who received isotretinoin or etretinate, 17 exhibited complete regression of lesions and 63 showed partial regression. In a recent study, the treatment of oral leukoplakia with isotretinoin prevented oral carcinogenesis (ref. 20). Laryngeal dysplasia, a precursor lesion of carcinoma of the larynx, has been treated with etretinate. Of 42 patients, $28(67 \%)$ achieved complete regression and $11(26 \%)$ partial regression. Mammary dysplasia in 12 patients was treated with vitamin A (retinol) at an oral dose of 150000 IU/day. Objective remission was observed in five patients and subjective remission in nine. Cervical dysplasia was treated topically with tretinoin. Of 74 evaluable cases, 24 responded with complete and four with partial remission. In 46 patients, there was very little or no response. Vulval dystrophy was treated with etretinate. In 16 of the 26 patients treated, objective and subjective improvements were obtained. Papilloma of the bladder was treated with tretinoin in a group of 15 patients: complete remission was obtained in four $(27 \%)$, while remission was only partial in seven (47\%). 
Myelodysplastic syndrome, considered as a precursor of leukemia, is influenced by isotretinoin. Of 69 patients treated, four $(6 \%)$ showed complete remission and $22(32 \%)$ partial remission.

From these therapeutic results, it may be concluded that some precursor lesions have been treated by retinoids with a certain degree of success. However, the results are not yet satisfactory, since for many precancerous lesions conventional therapy is superior to treatment with retinoids.

\section{THERAPY OF CANCER}

Retinoids given as monotherapy have given, in most instances, unsatisfactory results (ref. 24). However, retinoid treatment led to limited therapeutic success in BCC and SCC of the skin, and cutaneous T-cell lymphoma. The only dramatic results achieved with monotherapy with a retinoid were in treatment of acute promyelocytic leukemia (APL) with tretinoin (refs. 25-28). Chinese clinicians claimed an $85 \%$ complete remission rate in a report on 787 patients with APL (ref. 29). In the western world and Japan, out of 228 published cases, 195 patients experienced complete remission, corresponding to $85.5 \%$. The induction of complete remission by tretinoin, followed by consolidation therapy with cytostatic agents such as daunomycin and cytosine arabinoside, produced a longer event-free survival than with chemotherapy alone (ref. 30). Remissions are obtained by differentiation of leukemic cells to phenotypically normal granulocytes. Recently, clinical trials have been performed with a combination of isotretinoin and interferon $\alpha$. SCC of the skin responded with a remission rate of $68 \%$ (ref. 31) and those of the cervix with $50 \%$ (ref. 32). Combination therapy was clearly superior to administration of the individual components.

All the above mentioned clinical results in prevention and therapy of preneoplastic and neoplastic conditions have led to a certain cautious optimism towards further progress in the practical usefulness of retinoids, given alone or in combination, e.g. with cytokines.

\section{MOLECULAR BIOLOGY OF RETINOIDS}

Studies on the mechanism of action of retinoids have progressed in the past few years with the discovery of the nuclear RA receptors (RAR). Retinoid binding proteins such as the cellular cytosolic RA-binding proteins I and II (CRABPI and CRABPII) have been well characterized (refs. 33,34). Although previously mistaken for receptors, these binding proteins are responsible for intracellular transport of retinoids and regulation of retinoid concentration.

To date, six nuclear retinoic acid receptors have been identified (ref. 35). They fall into two subclasses: RAR $\alpha$, $B$ and $\gamma$, which have a high affinity for all-trans-RA, and $\operatorname{RXR} \alpha, \beta$ and $\gamma$, which do not bind to this ligand. However, 9-cis RA has been shown to be a ligand for RXR (refs. 36,37). All these receptors belong to the superfamily of steroid-thyroid hormone receptors, which share sequence similarities in the DNA-binding domain. These receptors presumably function in the following way (Fig. 2): RA or other retinoids first bind to ligandbinding domain $\mathrm{E}$ of the receptor, perhaps inducing a conformational change in the receptor. The activated receptor then activates or represses the transcription of genes containing a RA-response element recognized by DNA-binding domain $C$ of the receptor. These transcriptional events result in the synthesis of mRNA and proteins which might be responsible for biological functions such as cell proliferation and differentiation. It is not known, however, whether individual receptors have specific biological functions. Two or more receptors might cooperate in the transcription of responsive genes and thus enable a specific biological function. Recently, the formation of heterodimers between RXR and RAR, as well as other members of the superfamily of nuclear hormone receptors, has been demonstrated. The complexity of the network of retinoid receptors might explain the pleiotropic biological effects of retinoids.

\section{BIOLOGY OF RETINOIDS}

Development and maintenance of normal tissue depends on an adequate balance between growth and differentiation. In malignancies, this equilibrium is disturbed. There is good evidence that the antitumor activity of retinoids is at least partially due to induction of cellular differentiation and/or inhibition of cell proliferation. The effect of retinoids on cell proliferation and differentiation based mainly on investigations using human transformed tumor cell lines, is discussed below, as well as the suppression of viral oncogene expression and the 
inhibition of angiogenesis by retinoids. These may contribute to the antitumor effect of retinoids. The investigations carried out center on the diverse action of various retinoids and combination with cytokines, growth factors and vitamin-D analogs.

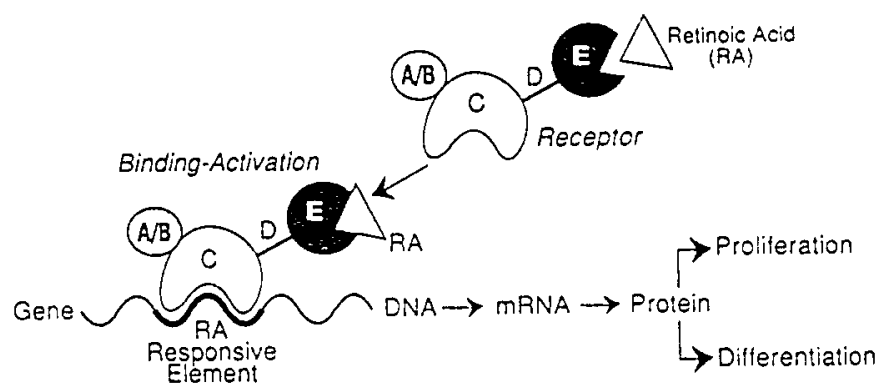

Fig. 2. Intracellular signalling system of retinoic acid receptors

\section{CELL DIFFERENTIATION}

Differentiation of a neoplastic cell into a phenotypically normal cell probably plays an important role in tumor therapy. Retinoids were shown in the 1970s to induce differentiation in a series of human and murine transformed cell lines such as the myelomonocytic leukemias HL-60 and U937 (ref. 38), neuroblastoma LA-N-1 (ref. 39), teratocarcinoma F9 (ref. 40) and embryonal carcinomas (ref. 41). Differentiation can be ascertained either morphologically or by means of specific markers characteristic of differentiated cells, e.g. in HL-60 cells by determining nitroblue tetrazolium reduction, an indicator of peroxide formation. In HL-60 cells, retinoids vary in their capacity to induce differentiation in the following order:

9-cis-RA > all-trans-RA > 13-cis-RA > acitretin (refs. 24,42-44; Fig. 3).

In many experiments, retinoids were investigated in combination with cytokines and vitamin-D analogs. Cytokines alone do not exert a significant induction of differentiation in HL-60 cells. However, when combined with retinoids, cytokines substantially potentiate the differentiation-inducing effect of retinoids (refs. 42,43). The highest degree of potentiation was achieved with Interferon $\gamma$ (IFN $\gamma$ ) and granulocyte colony-stimulating factor (G-CSF). Depending on the retinoid used, also IFN $\alpha$, IFNB, Interleukin-1 (IL-1), IL-4 and tumor necrosis factor $\alpha(T N F \alpha)$ potentiated differentiation (Fig. 4), whereas IL-2, epidermal growth factor (EGF) and tumor growth factor $B(T G F B)$ were inactive in this respect.

The active metabolite of vitamin $D, 1 \alpha, 25$-dihydroxy-vitamin $D_{3}\left(V D_{3}\right)$, as well as analogs of $V D_{3}$ when administered alone induced differentiation in the transformed hemopoietic cell lines HL-60 and U937, at concentrations lower than for retinoids (refs. 45-48). When $\mathrm{VD}_{3}$ was combined with retinoids, a synergistic effect was observed, e.g. with all-trans-RA (refs. 49-51) and particularly with 9-cis-RA (ref. 44; Fig. 5).

\section{CELL PROLIFERATION}

In addition to induction of differentiation, the antitumor effect of retinoids has been associated with a direct antiproliferative effect. An inhibiting effect of all-trans-RA on proliferation has been demonstrated in many human transformed epithelial cell lines, e.g. mammary carcinoma, melanoma and a series of SCC of various organs (refs. 52-55). All-trans-RA, 13-cis-RA, 9-cis-RA and acitretin vary to some degree in their antiproliferative activity, depending on the cell line used (refs. 44,56,57). Combination of retinoids with cytokines led to an increased inhibition of proliferation in many cancer cell lines. Depending on which of the four human carcinoma cell lines were used, namely MCF7 (mammary carcinoma), SCC4, SCC15 (SCC of the tongue) or A431 (SCC of the vulva), the various cytokines tested had quantitatively different synergistic effects (ref. 56). IFN $\alpha$ was most consistent in intensifying the inhibiting effect of retinoids on proliferation (Fig. 6). However, TGFB, EGF, TNF $\alpha$ and IFN $\gamma$ also augmented retinoid-induced antiproliferative activity. $\mathrm{VD}_{3}$ alone also exerts an antiproliferative effect on a series of transformed human cell lines originating from melanoma and carcinomas of breast and colon (refs. 58,59). This has also been demonstrated for analogs that display less influence on calcium metabolism (refs. $60,61)$. The combination of all-trans-RA with $\mathrm{VD}_{3}$ leads to a substantial increase in inhibition of proliferation (ref. 62). 

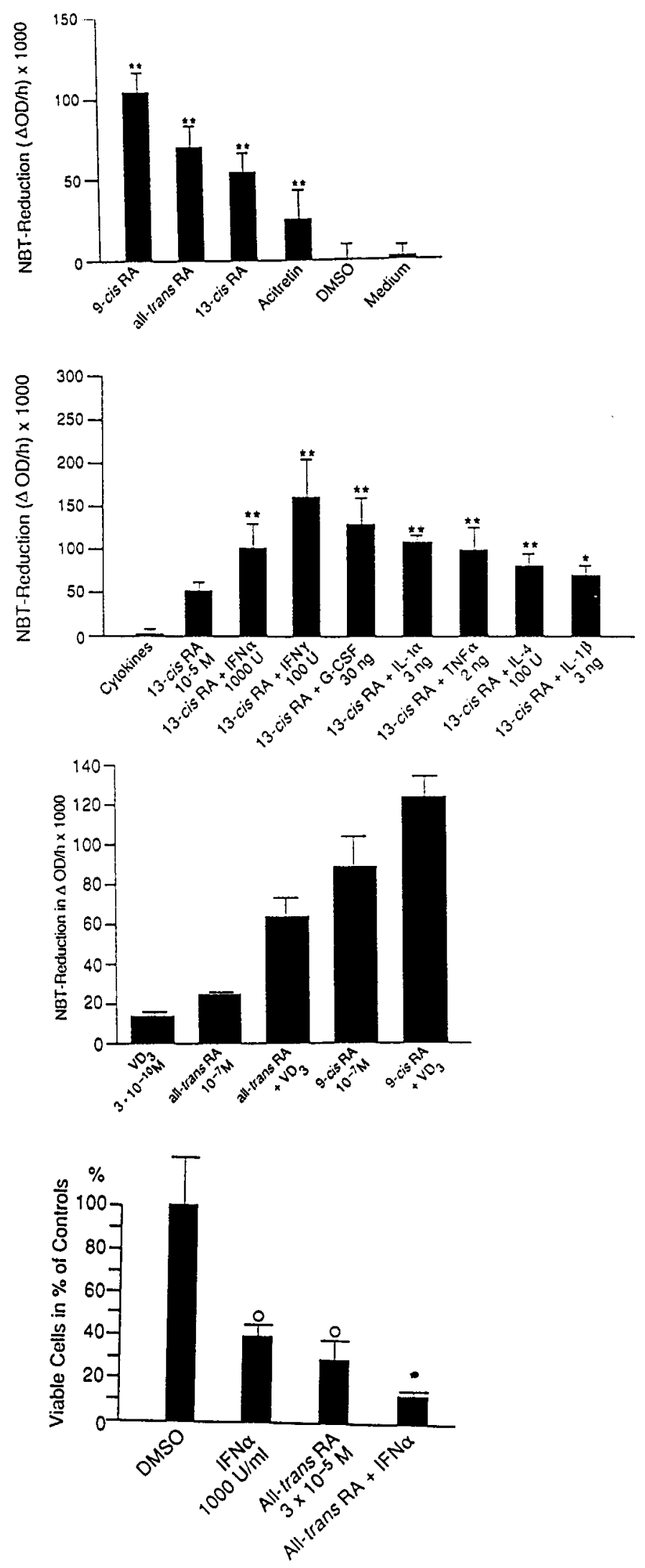

Fig. 3. Induction of differentiation in HL- 60 cells by various retinoids $\left(10^{-6} \mathrm{M}\right)$. $^{* *} \mathrm{p}<0.005$ compared with DMSO control (Student's t-test).

Fig. 4. Induction of differentiation in HL-60 cells by 13 -cis-RA or cytokines alone and their combination. Concentrations of cytokines are given per $\mathrm{ml}$. ${ }^{*} \mathrm{p}<0.05,{ }^{* *} \mathrm{p}<0.005$

(Student's t-test). By courtesy of Karger, Basle (ref. 42).

Fig. 5. Induction of differentiation in HL- 60 cells by all-trans and 9-cis$\mathrm{RA}, \mathrm{VD}_{3}$ and their combination. $p<0.005$ when combinations were compared with $R A$ and $V D_{3}$, given alone (Welch-Aspin test).

Fig. 6. Inhibition of proliferation in SCC 15 cells by all-trans-RA, IFN $\alpha$ and their combination. $\circ \mathrm{p}<0.05$ by comparison with the DMSO control (Student's t-test). ${ }^{*} p<0.05$ by comparison with all-trans-RA and IFN $\alpha$ given alone (Welch-Aspin test). 


\section{VIRAL ONCOGENES}

A high percentage of anogenital cancers harbor human papillomaviruses (HPV), especially HPV 16 and 18 . These high-risk types of HPVs are thought to be causally involved in the pathogenesis of these cancers, particularly cervical carcinoma, inducing cervical intraepithelial neoplasia which progresses to invasive carcinoma. The oncogenic potential of these HPVs has been attributed primarily to two early genes, E6 and E7. Cervical carcinoma HeLa and HeLa hybrid cell lines containing HPV-18 have been used to investigate the effect of retinoids on growth and oncogene expression in vitro. In parallel with growth inhibition by all-trans-RA, 13-cisRA and 9-cis-RA, HPV mRNA levels were down-regulated due to transcriptional repression (refs. 63,64). In addition to retinoids, IFN $\alpha$ and IFN $\gamma$ inhibited transcription of E6/E7 mRNA in human cervical epithelial cell lines harboring HPV 16 and 18 (refs. 65,66). It is possible that combination of retinoids and interferons would synergistically decrease HPV oncogene expression.

\section{ANGIOGENESIS}

Evidence is accumulating that angiogenesis plays an important role in growth of neoplasms. Tumor growth beyond a certain size, i.e., a few $\mathrm{mm}^{3}$, is dependent on formation of new blood vessels that are needed to deliver oxygen and nutrients to the tumor. Compounds inhibiting angiogenesis might therefore contribute to antitumor therapy (ref. 67). Antiangiogenic drugs may act by inhibiting tumor cell release of angiogenic factors, by blocking activity of angiogenic factors or by various ways of unspecific inhibition of new capillary formation (Ref. 68). Among other compounds, retinoids (ref. 69,70), vitamin D analogs (ref. 71) and IFN $\alpha$ (ref. 72) have been reported to possess antiangiogenic properties. Further investigations have been performed recently on the effects of these compounds, either alone or in combination, on tumor cell line-induced angiogenesis (ref. 73). A series of HPV 16 and 18 harboring cell lines, either tumorigenic or non-tumorigenic, were used. Balb/c mice were injected intraperitoneally on five consecutive days with test compounds. After total-body X-ray exposure, human tumor cells were injected intradermally. Three days later, the newly formed blood vessels at the skin injection site were counted. All-trans-RA, 13-cis-RA, 9-cis-RA, acitretin and the arotenoid Ro 40-8757 decreased the angiogenic potential of the tumorigenic cell lines HeLa, SKv-e2 and SKv-12. IFN $\alpha$ and VD $_{3}$ also inhibited tumorigenic cell line-induced angiogenesis. Combination of retinoids with IFN $\alpha$ (Fig. 7) and $\mathrm{VD}_{3}$ produced a substantially higher degree of antiangiogenesis than did either compound alone.

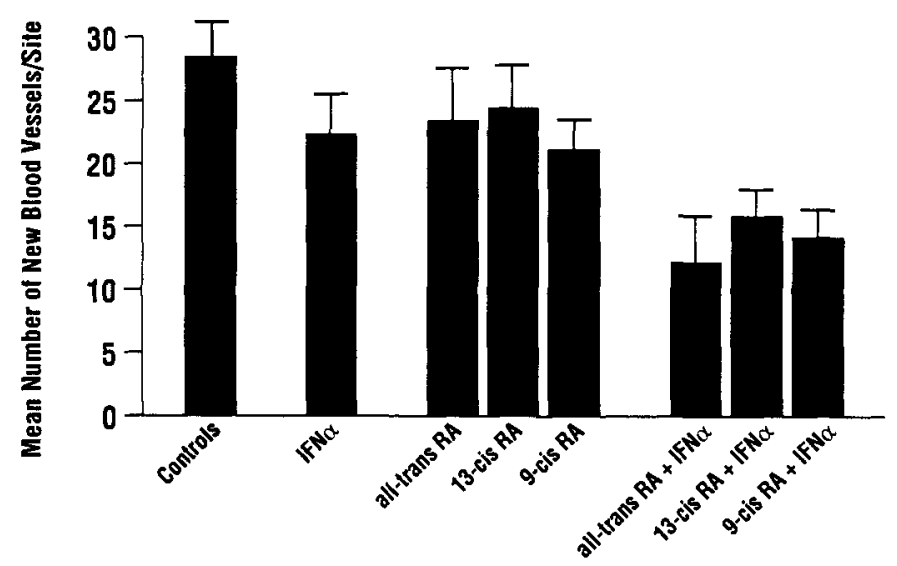

Fig. 7. Inhibition of HPV-harboring, tumorigenic SKv-e2 cell-induced angiogenesis by three retinoic acid isomers $(2,5 \mathrm{mg} / \mathrm{kg} / \mathrm{day}$ i.p.), IFN $\alpha(5000 \mathrm{U} / \mathrm{kg} /$ day i.p. $)$ and their combination. $p<0.001$ when RAs and IFN $\alpha$ were compared with controls and when combinations were compared with RAs and IFNa given alone (Student's t-test).

\section{OUTLOOK}

While retinoids have already established themselves in the successful treatment of various dermatological diseases such as acne, psoriasis and other keratinizing dermatoses, the clinical use of retinoids in oncology is still in its infancy. Results from preclinical studies and clinical trials have resulted in cautious optimism that retinoids may prove to be useful in prevention and therapy of various types of cancer. The discovery of new retinoids with a more favorable therapeutic index is, however, mandatory for these treatments to become acceptable for long-term preventive therapies. 
Improved therapeutic results can also be expected by combination of retinoids with other antitumor agents (cytokines, vitamin-D analogs and cytostatic agents), generating a synergism between antiproliferative, differentiation-inducing, immunomodulatory, oncogene-suppressive and antiangiogenic effects.

Differentiation therapy of cancer appears to be a particularly promising approach, since it represents a departure from the pharmacological principle of cell destruction to the physiological principle of conversion of neoplastic cells into differentiated, phenotypically normal cells.

In spite of enormous progress in the field of nuclear retinoid receptors, we still know very little about the specific biological function assigned to each receptor. The new tools supplied by molecular and cell biology may help in the design of tailor-made retinoids for specific neoplastic diseases. For the time being, serendipity will certainly still play a role in our efforts to improve the therapeutic results with retinoids in cancer.

\section{REFERENCES}

1. Y.Fujimaki, J. Cancer Res., 10, 469-477 (1926).

2. S. Mori, Bull. Johns Hopkins Hosp., 33, 357-359 (1922).

3. S.B. Wolbach and P.R. Howe, J. Exp. Med., 42, 753-778 (1925).

4. S.B. Wolbach and P.R. Howe, Arch. Pathol, 5 , 239-253 (1928).

5. W. Bollag, Internat. J. Vit. Res., 40, 299-314 (1970).

6. W. Bollag and H.R. Hartmann, Cancer Surv., 2, 293-314 (1983).

7. R.C. Moon and L.M. Itri, in The Retinoids. Vol. 2 (M.B. Sporn, A.B. Roberts and D.S. Goodman, eds) pp. 327-371, Academic Press, Orlando (1984).

8. S.M. Lippman, J.F. Kessler and F.L. Meyskens, Cancer Treatment Rep., 71, 493-515 (1987).

9. W. Bollag, Eur. J. Cancer, $\underline{8}, 689-693$ (1972).

10. W. Bollag, Eur. J. Cancer, $11,721-724$ (1975).

11. R.C. Moon, R.G. Mehta and D.L. McCormick, in Cancer: Etiology and Prevention (R.G. Crispen, ed) pp. 275-287, Elsevier, Amsterdam (1983).

12. M.B. Sporn, R.A. Squire, C.C. Brown, J.M. Smith, M.L. Wenk and S. Springer, Science, $\underline{195}, 487-489$ (1977).

13. M.B. Sporn, N.M. Dunlop, D.L. Newton and J.M. Smith, Fed. Proc., 35, 1332-1338 (1976).

14. O. Braun-Falco, A. Galosi, M. Dom and G. Plewig, Hautarzt, $\underline{33}, 445-448$ (1982).

15. K.H. Kraemer, J.J. DiGiovanna, A.N. Moshell, R.E. Tarone and G.L. Peck, N. Engl. J. Med, 318, 1633-1637 (1988).

16. L. Schnitzler, Ann. Dermatol. Venereol., 114, 1537-1543 (1987).

17. J.W. Kelly, J. Sabto, F.W. Gurr and F. Bruce, Lancet, 338, 1407 (1991).

18. G.L. Peck, in Retinoids: New Trends in Research and Therapy (J.H. Saurat, ed) pp. 345-355, Karger, Basel (1985).

19. G.L. Peck, J.J. DiGiovanna, D.S. Sarnoff, E.G. Gross, D. Butkus, T.G. Olsen and F.W. Yoder, J. Am. Acad. Dermatol. 19, 176-185 (1988).

20. S.M. Lippman, J.G. Batsakis, B.B. Toth, R.S. Weber, J.J. Lee, J.W. Martin, G.L. Hays, H. Goepfert and W.K. Hong, N. Engl. J. Med., 328, 15-20 (1993).

21. O. Alfthan, J. Tarkkanen, P. Gröhn, E. Heinonen, S. Pyrhönen and K. Säilä, Eur. Urol., 9, 6-9£ (1983).

22. U.E. Studer, C. Biedermann, D. Chollet, P. Karrer, R. Kraft, H. Toggenburg and F. Vonbank, J. Urol., 131, 47-49 (1984).

23. W.K. Hong, S.M. Lippman, L.M. Itri, D.D. Karp, J.S. Lee, R. Byers, S. Schantz, A. Kramer, R. Lotan, L. Peters, I. Dimery, B. Brown and H. Goepfert, N. Engl. J. Med., 323, 795-801 (1990).

24. W. Bollag and E.E. Holdener, Ann. Oncol., 3, 513-526 (1992).

25. L. Degos, C. Chomienne, M.T. Daniel, R. Berger, H. Dombret, P. Fenaux and S. Castaigne, Lancet, $\underline{336}$, 1440-1441 (1990).

26. M.E. Huang, Y.C. Ye, S.R. Chen, J.R. Chai, J.X. Lu, L. Zhoa, L. Gu and Z.Y. Wang, Blood, $\underline{72}$, 567-572 (1988).

27. R. Ohno, T. Ohshima, H. Dohi, T. Shinoura, T. Fujimoto, T. Kobayashi, A. Hiraoka, H. Mizoguchi, T. Murase and T. Naoe, Haematologica 76 (Suppl. 4), N 152 (1991).

28. R.P. Warrell, S.R. Frankel, W.H. Miller, D.A. Scheinberg, L.M. Itri, W.N. Hittelman, R. Vyas, M. Andreeff, A. Tafuri, A. Jakubowski, J. Gabrilove, M.S. Gordon and E. Dmitrovsky, N. Engl. J. Med., 324, 1385-1393 (1991).

29. Z. Chen, G.L. Sun, S.J. Chen, J.H. Tong, S. Dong, J.R. Cai and Z.Y. Wang, In Retinoids. New Trends in Research and Clinical Applications. Palermo, Abstract booklet p. 102 (1991). 
30. P. Fenaux, M.C. Robert, S. Castaigne, E. Archimbaud, C. Chomienne, H. Link, A. Guerci, D. Bowen, M. Sanz, M. Fey, N. Fegueux, C. Chastang and L. Degos, Proc. Amer. Soc. Clin. Oncol., 12, 300, Abstract 983 (1993).

31. S.M. Lippman, D.R. Parkinson, L.M. Itri, R.S. Weber, S.P. Schantz, D.M. Ota, M.A. Schusterman, I.H. Krakoff, J.U. Gutterman and W.K. Hong, J. Natl. Cancer Inst., 84, 235-241 (1992).

32. S.M. Lippman, J.J. Kavanagh, M. Paredes-Espinoza, F. Delgadillo-Madrueño, P. Paredes-Casillas, W.K. Hong, E. Holdener and I.H. Krakoff, J. Natl. Cancer Inst., 84, 241-245 (1992).

33. R. Blomhoff, M.H. Green, T. Berg and K.R. Norum, Science, 250, 399-404 (1990).

34. F. Chytil and D.E. Ong, in The Retinoids. Vol. 2 (M.B. Sporn, A.B. Roberts and D.S. Goodman, eds) pp. 89-123, Academic Press, Orlando (1984).

35. M. Leid, P. Kastner and P. Chambon, T.I.B.S., 17, 427-433 (1992).

36. A.A. Levin, L.J. Sturzenbecker, S. Kazmer, T. Bosakowski, C. Huselton, G. Allenby, J. Speck, C.I. Kratzeisen, M. Rosenberger, A. Lovey and J.F. Grippo, Nature, 355, 359-361 (1992).

37. R.A. Heyman, D.J. Mangelsdorf, J.A. Dyck, R.B. Stein, G. Eichele, R.M. Evans and C. Thaller, Cell, $\underline{68}$, 397-406 (1992).

38. T.R. Breitman, B.R. Keene and H. Hemmi, Cancer Surv., 2, 263-291 (1983).

39. N. Sidell, J. Natl. Cancer Inst., 68, 589-593 (1982).

40. S. Strickland and V. Mahdavi, Cell, $15,393-403$ (1978).

41. A.M. Jetten, M.E.R. Jetten and M.I. Sherman, Exp. Cell Res., 124, 381-391 (1979).

42. W. Bollag and R. Peck, in Retinoids: 10 Years On (J.H. Saurat, ed) pp. 127-138, Karger, Basel (1991).

43. R. Peck and W. Bollag, Eur. J. Cancer, 27, 53-57 (1991).

44. M. Brockhaus and W. Bollag, unpublished.

45. L. Binderup and E. Bramm, Biochem. Pharmacol., 37, 889-895 (1988).

46. D.M. McCarthy, J.F. San Miguel, H.C. Freake, P.M. Green, H. Zola, D. Catovsky and J.M. Goldman, Leukemia Res., 7, 51-55 (1983).

47. I. Olsson, U. Gullberg, I. Ivhed and K. Nilsson, Cancer Res., 43, 5862-5867 (1983).

48. J.Y. Zhou, A.W. Norman, M. Lübbert, E.D. Colin, M.R. Uskokovic and H.P. Koeffler, Blood, 74, 82-93 (1989).

49. B.T. Dore, M.R. Uskokovic and R.L. Momparler, Proc. Amer. Assoc. Cancer Res., 33, 442, Abstract 2640 (1992).

50. U. Gullberg, E. Nilsson, S. Einhom and I. Olsson, Exp. Hematol., 13, 675-679 (1985).

51. C. Miyaura, E. Abe, T. Suda and T. Kuroki, Cancer Res. 45, 4244-4248 (1985).

52. A.M. Jetten, J.S. Kim, P.G. Sacks, J.I. Rearick, D. Lotan, W.K. Hong and R. Lotan, Int. J. Cancer, $\underline{45}, 195-$ 202 (1990).

53. R. Lotan, Biochim. Biophys. Acta, 605, 33-91 (1980).

54. M. Ponec, A. Weerheim, J. Kempenaar and J. Boonstra, In Vitro Cell. Dev. Biol., 24, 764-770 (1988).

55. P.G. Sacks, V. Oke, B. Amos, T, Vasey and R. Lotan, Int. J. Cancer, 44, 926-933 (1989).

56. W. Bollag, R. Peck and J.R. Frey, Cancer Lett., 62, 167-172 (1992).

57. J.R. Frey, R. Peck and W. Bollag, Cancer Lett., 57, 223-227 (1991).

58. C. Chouvet, E. Vicard, M. Devonec and S. Saez, J. Steroid Biochem., 24,373-376 (1986).

59. R.J. Frampton, S.O. Omond and J.A. Eisman, Cancer Res., 43, 4443-4447 (1983).

60. J. Abe, T. Nakano, Y. Nishii, T. Matsumoto, E. Ogata and K. Ikeda, Endocrinology, 129, $832-837$ (1991).

61. K.W. Colston, S.K. Chander, A.G. Mackay and R.C. Coombes, Biochem. Pharmacol., 44, 693-702 (1992).

62. M. Koga and R.L. Sutherland, J. Steroid Biochem. Molec. Biol., 39, 455-461 (1991).

63. D. Bartsch, B. Boye, C. Baust, H. zur Hausen and E. Schwarz, EMBO J., 11, 2283-2291 (1992).

64. E. Schwarz, unpublished.

65. C.D. Woodworth, U. Lichti, S. Simpson, C.H. Evans and J.A. DiPaolo, Cancer Res., 52, 456-463 (1992).

66. A. Nawa, Y. Nishiyama, N. Yamamoto, K. Maeno, S. Goto and Y. Tomoda, Biochem. Biophys. Res. Comm., 170, 793-739 (1990).

67. J. Folkman, Semin. Cancer Biol., 3 , 65-71 (1992).

68. R. Bicknell and A.L. Harris, Semin. Cancer Biol., 3, 399-407 (1992).

69. L. Rudnicka, M. Marczak, A. Szmurlo, B. Makiela, A. Skiendzielewska, M. Skopinksa, S. Majewski and S. Jablonska, Skin Pharmacol, 4, 150-153 (1991).

70. A. Szmurlo, M. Marczak, S. Jablonska and W. Bollag, Dermatology, 184, 116-119 (1992).

71. T. Oikawa, K. Hirotani, H. Ogasawara, T. Katayama, O. Nakamura, T. Iwaguchi and A. Hiragun, Eur. J. Pharmacol., 178, 247-250 (1990).

72. Y.A. Sidky and E.C. Borden, Cancer Res., 47, 5155-5161 (1987).

73. S. Majewski, A. Szmurlo, M. Marczak, W. Bollag and S. Jablonska, J. Natl. Cancer Inst., submitted. 